\title{
Delayed total hip arthroplasty after failed treatment of acetabular fractures: an 8- to 17-year follow-up study
}

\author{
Tao Wang ${ }^{1}$, Jun-Ying Sun ${ }^{2^{*}}$, Jun-Jun Zha ${ }^{2}$, Chao Wang ${ }^{2}$ and Xi-Jiang Zhao ${ }^{1^{*}}$
}

\begin{abstract}
Background: Delayed total hip arthroplasty (THA) is a reliable procedure following failed treatment of acetabular fractures. The aim of the present study was to evaluate the influence of the type of fracture treatment and modern ceramic bearing on the clinical outcomes of delayed THA.
\end{abstract}

Methods: Between January 1997 and January 2008, 33 patients (33 hips) underwent cementless THA after failed acetabular fractures. Twenty-one were initially treated by open reduction internal fixation (ORIF) and 12 had non-ORIF. Joint articulation was either conventional metal-on-polyethylene (MOP) or ceramic-on-ceramic (COC). Intraoperative measures and preoperative and follow-up clinical, radiological, and functional outcomes were compared between the ORIF and non-ORIF groups.

Results: Surgery duration, blood loss, and transfusion requirement were greater in the ORIF group than in the non-ORIF group $(p<0.05)$. Significant improvement in Harris Hip Scores was seen post-surgery in both groups. However, a significant difference in the mean Harris Hip Score was not observed between the two groups $(p=0.57)$. Six patients in the ORIF group required acetabular reconstructive procedures to address bony defects compared to seven patients in the non-ORIF group ( $p=0.09)$. The rate of anatomical restoration was $58.3 \%(7 / 12)$ in the non-ORIF group and $42.9 \%(9 / 21)$ in the ORIF group ( $p=0.12$ ). Radiolucent lines were observed in the MOP group and none in the COC group. Overall survival rate was similar in both groups ( $p=0.85$ ): $89.3 \%$ in the ORIF group and $87.5 \%$ in the non-ORIF group.

Conclusion: Delayed THA with previous acetabular fractures is a challenging procedure. Initial fracture treatment does not influence the outcome of delayed THA, and modern ceramic bearing has promising results in the long-term follow-up.

Keywords: Acetabular fracture, Total hip arthroplasty, Cementless cup, Ceramic-on-ceramic

\section{Background}

Acetabular fractures are serious injuries which can lead to progressive impairment of hip function [1]. Anatomic reduction with rigid internal fixation of the acetabulum has been shown to restore hip function and prevent long-term complications. Unfortunately, many patients with fractures of the acetabulum still suffer posttraumatic arthritis or femoral head necrosis regardless of whether operative or non-operative intervention was chosen as the initial treatment. These irreparable complications may occur as a result of residual articular incongruity, early articular cartilage

\footnotetext{
* Correspondence: sunjunyingsuda@163.com; ouyang520@jiangnan.edu.cn 'Department of Orthopedic Surgery, Affiliated Hospital of Jiangnan University, 200 Huihe Rd, Wuxi 214062, Jiangsu, China

${ }^{2}$ Department of Orthopedic Surgery, The First Affiliated Hospital of Soochow University, 188 Shizi Street, Suzhou 215006, Jiangsu, China
}

damage, inaccurate placement of implant fixation, and disruption of femoral head blood provision. Even when near-anatomic reductions are achieved, the reported incidence of posttraumatic arthritis has been varied between 27 and $37 \%$ [2], with the incidence of subsequent total hip arthroplasty (THA) ranging from 8 to $23 \%$ [2-4].

When posttraumatic arthritis and femoral head necrosis occur, THA is a rational salvage procedure. Retained internal fixation implants, scar tissue, and residual acetabulum bone defects cause subsequent THAs to be more complex than routine THA $[5,6]$. Moreover, the results of these THAs presented to be inferior to THA performed after primary osteoarthritis [7-9], attributable to the extent of loss of bone stock and abnormal anatomy after trauma [9-11]. Therefore, some authors recommended that initial

(C) The Author(s). 2018 Open Access This article is distributed under the terms of the Creative Commons Attribution 4.0 International License (http://creativecommons.org/licenses/by/4.0/), which permits unrestricted use, distribution, and 
open reduction internal fixation (ORIF) is essential to restore the bony anatomy for subsequent THA, decreasing its complexity and improving component survival [12-14]. Conversely, others have postulated that initial ORIF increases the rate of infection, blood loss, and surgery time $[6,15]$. Furthermore, there is no explicit evidence that ORIF improves the success rate of subsequent THA [16].

Additionally, patients with acetabular fractures are generally young and have posttraumatic osteoarthritis that results from a high activity level. A series reports high failure rates of subsequent THA, which have been attributed to younger age and increased activity $[9,11]$. Therefore, in those patients, alternative bearing surfaces should reduce polyethylene wear and osteolysis that have been present in previous studies using traditional metal-on-polyethylene (MOP). Recently, modern ceramic-on-ceramic (COC) THA has demonstrated decreased risk of wear-induced osteolysis over MOP and then improved the long-term outcomes of THA $[17,18]$.

Therefore, the primary aim of the present study was to evaluate the influence of the mode of treatment of fracture, conservative treatment or ORIF, on the clinical outcomes of salvage THA. The secondary aim was to evaluate the long-term results associated with modern COC THA after failed acetabular fractures.

\section{Methods}

All patients who underwent THA for posttraumatic osteoarthritis or femoral head necrosis due to acetabular fractures during the period from January 1997 to January 2008 were eligible for inclusion in this study. Exclusion criteria were incomplete radiographic or clinical date and without adequate follow-up. Two patients (2 hips) had died of causes unrelated to surgery. Five patients (5 hips) were lost to follow-up. Thus, 33 remaining patients (33 hips) were available for review. Patient demographics and characteristics of the fractures are summarized in Table 1. This study was approved by our institutional review board.

\section{Surgical technique and implants}

Delayed THA was performed through a posterior approach in 25 hips, and a modified Hardinge approach in 8 hips. The acetabulum was prepared for routine primary THA. Retained hardware or heterotopic bone was not routinely removed unless it interfered with reaming and placement of the cup. Acetabular bone deficiency was classified based on American Academy of Orthopedic Surgeons (AAOS) classifications [19]. We adopted impaction bone grafting (IBG) combined with a cementless cup to address acetabular bone defects with segments of bone or morselized cancellous bone taken from the resected femoral head. Cementless acetabular fixation was used in all cases using a press-fit technique. If the initial press-fit fixation did
Table 1 Patient demographics and fracture features

\begin{tabular}{|c|c|}
\hline \multicolumn{2}{|l|}{ Gender } \\
\hline Male/female & $21 / 12$ \\
\hline Mean age (years) & $\begin{array}{l}45.1 \pm 9.3 \\
\text { (range, 25-68) }\end{array}$ \\
\hline Mean body mass index $\left(\mathrm{kg} / \mathrm{m}^{2}\right)$ & $\begin{array}{l}23.5 \pm 2.9 \\
\text { (range, 17.0-32.9) }\end{array}$ \\
\hline Interval time between fracture and THA (month) & $\begin{array}{l}58 \\
\text { (range, 4-240) }\end{array}$ \\
\hline \multicolumn{2}{|l|}{ Preoperative diagnosis } \\
\hline Posttraumatic osteoarthritis & 23 \\
\hline Femoral head necrosis & 10 \\
\hline \multicolumn{2}{|l|}{ Fracture patterns } \\
\hline \multicolumn{2}{|l|}{ Simple factures } \\
\hline Posterior column & 4 \\
\hline Posterior wall & 7 \\
\hline Anterior column & 2 \\
\hline Anterior wall & 0 \\
\hline Transverse & 3 \\
\hline \multicolumn{2}{|l|}{ Complex fractures } \\
\hline Posterior wall + posterior column & 3 \\
\hline Transverse + posterior wall & 6 \\
\hline Both column & 4 \\
\hline T-shaped & 2 \\
\hline Anterior column + posterior hemitransverse & 3 \\
\hline \multicolumn{2}{|l|}{ Fracture treatment } \\
\hline ORIF & 21 \\
\hline Non-ORIF & 12 \\
\hline
\end{tabular}

not provide sufficient cup stability, additional screw fixation was conducted. Joint articulation was either MOP or COC. MOP was used in 12 hips. A Synergy stem and Reflection acetabular cup (Smith \& Nephew, USA) were used in six hips, a Self-Locking stem and SPH cup (Lima, Italy) was used in four hips, and a Bi-Metric stem and Universal cup (Biomet, USA) in two hips. COC was used in 21 hips, in which a C2 stem and "Sandwich" cup (Lima, Italy) was used in five hips, an F2L stem and "Sandwich" cup (Lima, Italy) in four hips, and an S-ROM stem and Duraloc cup (Depuy, USA) in 12 hips.

\section{Perioperative regimen}

Patients received antibiotic prophylaxis at $0.5 \mathrm{~h}$ before surgery and within the first $24 \mathrm{~h}$ postoperatively. Low-molecular-weight heparin was routinely administered for preventing thromboembolism. No patient received prophylaxis against heterotopic ossification. All patients were allowed to do quadriceps strengthening exercises and passive movements following surgery. Patients that had received a bone graft were instructed to restrict 
movement to touch-down weight-bearing for 6 weeks then gradually increase this to full weight-bearing thereafter.

\section{Clinical and radiographic evaluation}

Clinical and radiographic examinations were performed at 6 weeks, 6 months, 1 year, and annually thereafter. Hip function was assessed using the Harris Hip Score (HHS) [20]. All plain radiographs qualified for evaluation of biomechanical reconstruction are shown in Fig. 1. Linear polyethylene wear was measured using the method of Pollock et al. [21] using Digimizer software. Radiolucent lines and osteolysis were evaluated on postoperative serial radiographs according to the method of DeLee and Charnley [22] and Gruen et al. [23] for the acetabulum and femur, respectively. Bony ingrowth was described according to the criteria of Engh et al. [24]. Heterotopic ossification was classified according to the system of Brooker et al. [25].

\section{Statistical methods}

Statistical analyses were performed using SPSS v19.0 (SPSS, USA) statistical software. All data were expressed as mean \pm standard deviation (SD) and were tested for equal variance using the Levene test. Categorical variables were evaluated using a chi-square test or Fisher's exact test for statistical significance. Continuous variables were assessed using a Student $t$ test. The level of significance was set at $p<0.05$. Survivorship analysis of reconstructions was assessed by the Kaplan-Meier. The endpoint was defined as a revision for any reason or definite radiographic signs of loosening.

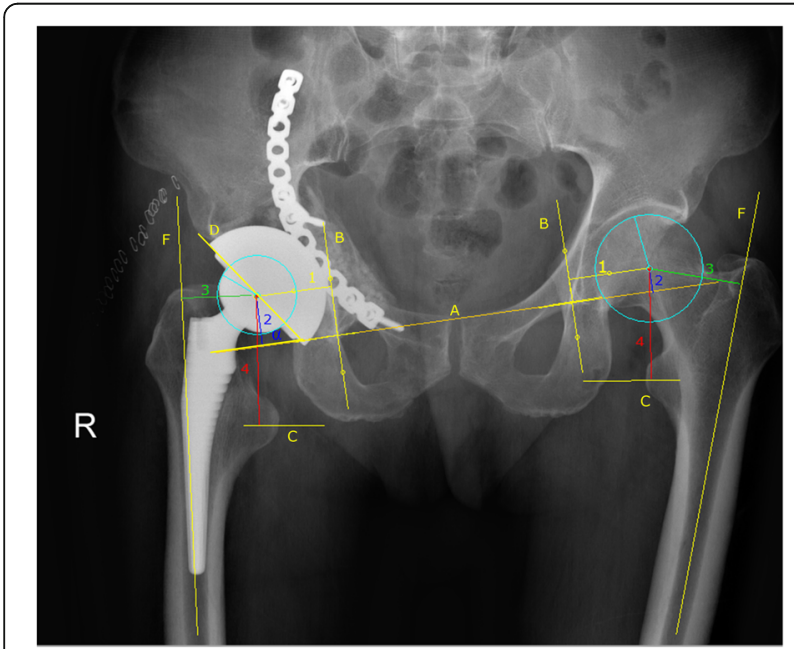

Fig. 1 Postoperative radiograph after THA with impacting bone grafting combined with a cementless cup. A, horizontal teardrop line; $B$, vertical teardrop line; $C$, midline lesser trochanter; $D$, a line along the lateral surface of the acetabular component; $F$, femoral shaft line. 1, horizontal hip center of rotation; 2, vertical hip center of rotation; 3 , horizontal femoral offset; 4 vertical femoral offset; $a$, the angle between a line drawn between line $A$ and line $D$

\section{Results}

Clinical outcomes

Mean follow-up time was $11.5 \pm 3.0$ years (range, 817 years) after primary THA. The mean duration between initial fracture and requirement for subsequent arthroplasty was not significantly different between the ORIF group and the non-ORIF group (52.8 months vs 62.4 months). Union was achieved in all fractures in the ORIF group, but four (33.3\%) non-unions were in the non-ORIF group. For subsequent THA, the non-union fractures were treated with rigid internal fixation and bone grafting. In the ORIF group, the retained hardware was removed either in part or in its entirety in four patients $(4 / 21)$ who had undergone prior ORIF of acetabular fractures. Six patients (6/21) in the ORIF group required acetabular reconstruction to address bony defects compared to seven patients $(7 / 12)$ in the non-ORIF group, although the difference was not statistically significant $(p=0.09)$. The comparison revealed that longer surgery occurred in the ORIF group (189 min for ORIF vs $143 \mathrm{~min}$ for non-ORIF, $p=0.02$ ) and greater blood loss (1289 ml for ORIF vs $750 \mathrm{ml}$ for non-ORIF, $p<0.01)$. Differences in the average perioperative transfusion requirements were also found (6.6 units for ORIF vs 3.5 units for non-ORIF, $p<0.01$ ) (Table 2).

Mean HHS improved across all patients from $44.0 \pm 11.9$ points (range, $27-58$ points) preoperatively to $88.6 \pm 5.1$ points (range, 74-94 points) at the final follow-up. Excellent scores were observed in 24 hips, good in 7 , and fair in 2. In the ORIF group, mean HHS increased from $45.9 \pm$ 12.1 points (range, $27-58$ points) to $89.0 \pm 5.4$ points (range, 74-94 points) $(p<0.05)$. In the non-ORIF patients, it improved from $40.8 \pm 11.3$ points (range, $29-58$ points) to $87.9 \pm 4.8$ points (range, $79-94$ points) $(p<0.05)$. However, difference in the mean HHS at final follow-up was not observed between the two groups $(p=0.57)$ (Table 2).

\section{Radiographic results}

Mean abduction angle was $33.8^{\circ} \pm 8.5^{\circ}$ (range, $16-54^{\circ}$ ). At the final radiographic follow-up, surviving implants showed radiographic evidence of stable bony ingrowth (Fig. 2). All bone grafts united with the host bone, without any graft resorption observed. No acetabular component loosening was observed in either group. In the ORIF group, two acetabular revisions were performed due to infection and a ceramic liner fracture. In the non-ORIF group, one patient had ceramic liner fracture and underwent acetabular revision. Failure defined as revision of the acetabular component for any reason, the Kaplan-Meier survivorship of the prostheses was $88.9 \%$ (95\% CI 76.9 100\%). Moreover, overall survival rate was similar in both groups $(p=$ 0.85): $89.3 \%$ in the ORIF group and $87.5 \%$ in the non-ORIF group (Fig. 3).

The impact of THA on biomechanical reconstruction parameters observed in the contralateral hip is shown in 
Table 2 Perioperative data for ORIF and non-ORIF groups

\begin{tabular}{llll}
\hline Variable & ORIF group & Non-ORIF group & $p$ value \\
\hline Sex (M/F) & $13 / 8$ & $8 / 4$ & 0.78 \\
Age at THA (years) & $44.9 \pm 10.5$ & $45.5 \pm 7.2$ & 0.86 \\
Interval time between fracture and THA (months) & $52.8 \pm 12$ & 7 & $0.4 \pm 20$ \\
Bone defects & 6 & & 0.09 \\
Fracture pattern & & $7 / 5$ & \\
$\quad$ Simple/complex & $8 / 13$ & & 0.26 \\
Harris hip score & & $40.8 \pm 11.3$ \\
$\quad$ Preoperative & $45.9 \pm 12.1$ & $87.9 \pm 4.8$ & 0.24 \\
$\quad$ At last follow-up & $89.0 \pm 5.4$ & $143 \pm 32$ & 0.57 \\
Surgery duration (min) & $189 \pm 57$ & $750 \pm 145$ & 0.02 \\
Blood loss (ml) & $1289 \pm 429$ & 3.5 & 0.00 \\
Perioperative transfusion requirements (u) & 6.6 & 0.00 \\
\hline
\end{tabular}

\section{$M$ male, $F$ female}

Mean \pm SD

Table 3, although there were no significant differences between the non-ORIF and ORIF groups. Among the 33 patients, reconstructed hip center within $20 \mathrm{~mm}$ of vertical and horizontal symmetry happened in 27 patients compared with the contralateral hip, including 16 patients (7 non-ORIF vs 9 ORIF) with anatomical restoration and 11 patients (5 non-ORIF vs 6 ORIF) with a reconstructed hip center within 10-20 mm of vertical and horizontal symmetry. The remaining six patients, who were all in the ORIF group, had a reconstructed hip center more than $20 \mathrm{~mm}$ beyond vertical or horizontal symmetry, or both. Therefore, the rate of anatomical restoration was 58.3\% (7/

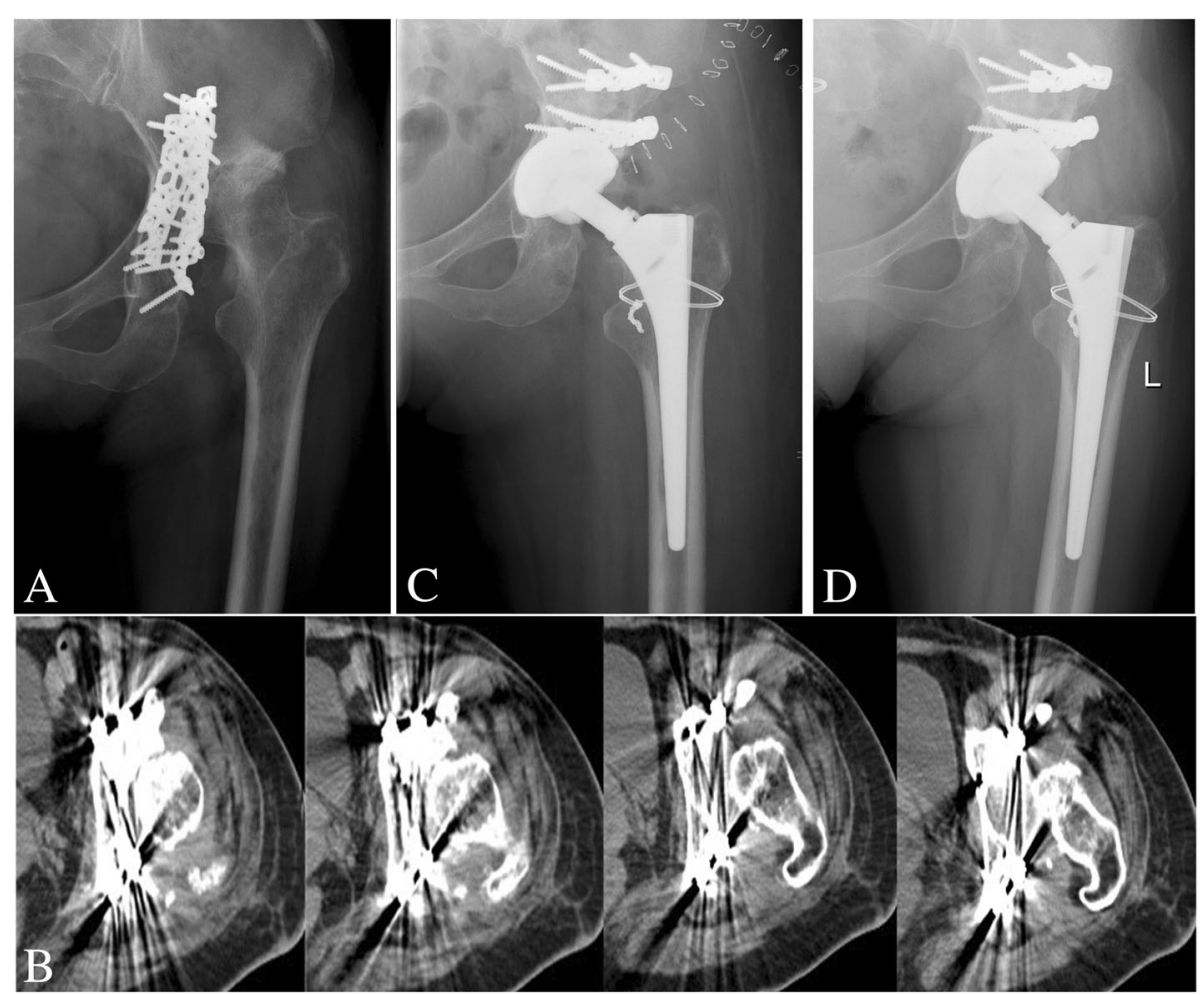

Fig. 2 Delayed total hip arthroplasty (THA) in a 51-year-old woman with posttraumatic arthritis secondary to acetabular fracture. a Preoperative radiograph. $\mathbf{b}$ Computed tomographic scans of the hip revealed the posterior acetabular wall defect. $\mathbf{c}$ Immediate postoperative $\mathrm{X}$-ray after acetabular reconstruction with the structure bone graft combined with cementless cup. d A 15 years' follow-up X-ray showed the graft had completely united and no loosening or osteolysis around the acetabular or femoral component 


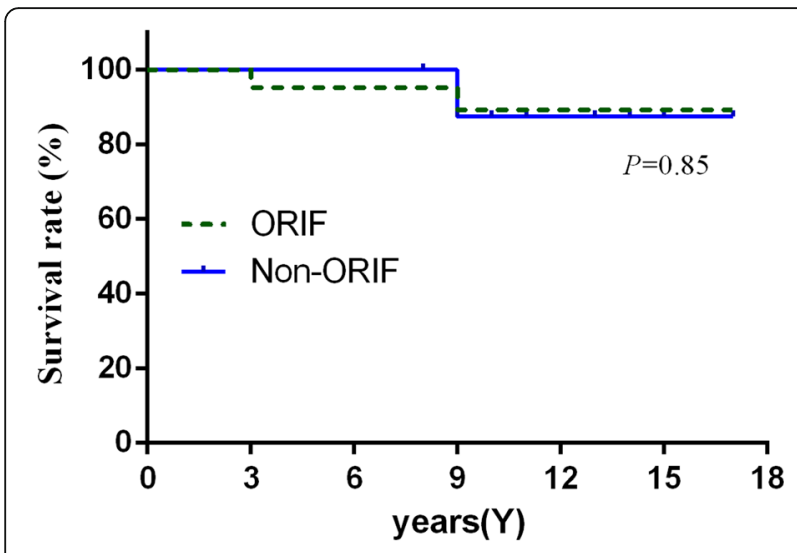

Fig. 3 Kaplan-Meier survival curves at a mean 11.5 years for all patients who performed THA after acetabular fracture with implant revision for any reason as an endpoint and due to loosening at the time follow-up as the other endpoint, respectively

$12)$ in the non-ORIF group and $42.9 \%(9 / 21)$ in the ORIF group $(p=0.12)$. Anatomical restoration was not related to the method of fracture treatment $(r=0.248, p=0.163)$.

Average rate of conventional linear polyethylene wear was $0.22 \pm 0.05 \mathrm{~mm} /$ year with a mean of 11.5 years in the MOP group. At the final follow-up, linear wear of the polyethylene insert was measured $>0.2 \mathrm{~mm} /$ year in eight cases. Among them, six acetabular components formed partial radiolucent lines at the bone-implant interface, observed in zone I in four hips and in zone III in two hips. On the femoral side, two stems had radiolucent lines in Gruen zone 1. This had not affected acetabular or femoral component stability, and they had not been revised. In contrast, no radiolucent lines or osteolysis was observed in any patient in the COC group (Fig. 4).

\section{Complications}

Heterotopic ossification was observed in ten patients (seven in the ORIF group, three in the non-ORIF group). No heterotopic bone caused any adverse clinical effects. One posterior dislocation occurred in the ORIF group, which was successfully managed with closed reduction. The sciatic nerve was injured before THA in two patients in the ORIF group. No patient had new or progressive sciatic nerve symptoms after THA. Additionally, three revisions were performed (two ORIF group and one non-ORIF). One patient in the ORIF group underwent a successful two-stage revision hip arthroplasty to control infection. Two "sandwich" liner fractures occurred in both ORIF and non-ORIF groups.

\section{Discussion}

When posttraumatic osteoarthritis develops secondary to acetabular fracture, THA is considered a reliable procedure to relieve pain and restore function $[8,26,27]$. Failed acetabular fractures after non-operative treatment often have bone defects, suffer non-union, or have residual pelvic deformity from malunion [11]. Similarly, following initial ORIF treatment, THA procedures not only faced the same difficulty as non-operatively treated fractures, but they also suffered problems related to previous surgery such as proliferative scar tissue, heterotopic bone formation, or obstructive hardware $[6,8,9,28]$. In our study, we observed that the surgery duration and blood loss were greater in the ORIF group than in the non-ORIF group. However, no significant difference in average HHS was observed at the final follow-up between the two groups (ORIF group 89 vs non-ORIF 87.9, $p=0.57$ ). In brief, performing a salvage THA following acetabular fracture is a challenging procedure. ORIF prior to THA resulted in more complex surgery which did not improve the final clinical outcome.

Acetabular bone defects and abnormal anatomy are contributing factors to the inferior THA outcomes experienced in the setting of previous acetabular fractures [7, 27]. Weber et al. [8] also demonstrated that large deficiencies in acetabular bone were associated with a poorer rate of long-term outcome after delayed THA. To restore bone stock and minimize acetabular deformity, various reconstruction techniques have been described to treat this issue effectively. IBG, a widely accepted technique for acetabular reconstruction after bone stock loss in revision THA, represents one option. Postoperative longevity of the acetabular component achieved from this technically demanding procedure is well documented in previous literature [29]. Based on this favorable experience, we reconstructed the acetabulum using the IBG technique with a cementless hemispherical cup in this study, obtaining sufficient host bone coverage and stability fixation (Fig. 2). Additionally, our results of THA in patients who were treated with ORIF for acetabular fractures demonstrated that ORIF did not reduce the incidence of bone defects compared with non-ORIF $(6 / 21$ vs $7 / 12, p=0.09)$. Furthermore, the

Table 3 Biomechanical parameters on the operated hip compared to the native contralateral hip (unilateral hip arthroplasty). Data are presented as mean (SD, range)

\begin{tabular}{llll}
\hline Parameter & Non-ORIF $(n=12)$ & ORIF $(n=21)$ & $p$ value \\
\hline Horizontal hip center of rotation & $+2.6( \pm 0.59,-7.9 \sim 10.3)$ & $-1.9( \pm 8.3,-20.6 \sim 12.2)$ & 0.130 \\
Vertical hip center of rotation & $+5.2( \pm 7.9,-11.3 \sim 14.2)$ & $+10.7( \pm 11.0,-21.7 \sim 27.2)$ & 0.134 \\
Horizontal femoral offset & $+1.4( \pm 8.6,-12.9 \sim 16.6)$ & $+4.2( \pm 10.3,-25.5 \sim 17.7)$ & 0.29 \\
Vertical femoral offset & $+5.0( \pm 12.9,-19.4 \sim 24.2)$ & $+9.1( \pm 7.8,-13.2 \sim 25.0)$ & 0.48 \\
\hline
\end{tabular}




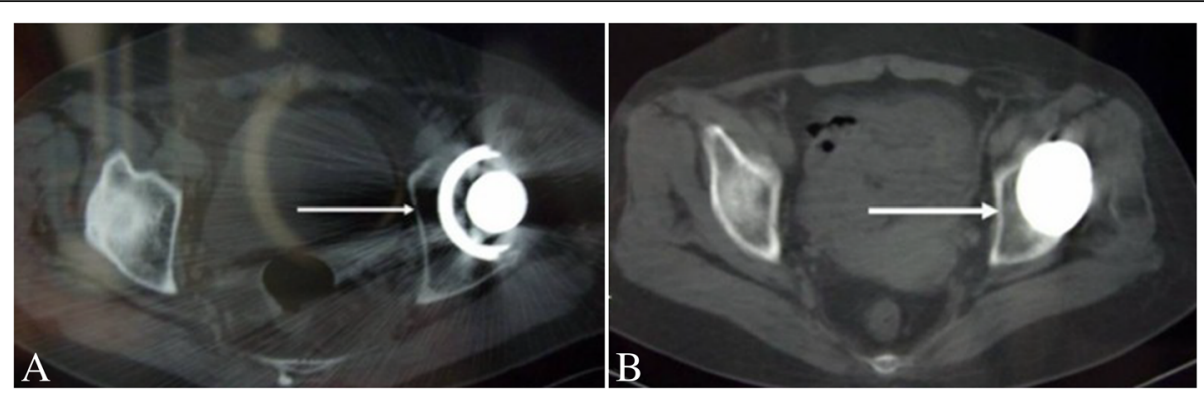

Fig. 4 a Local osteolysis around the acetabular was observed by computed tomography (CT) in the metal-on-polyethylene group. b No evidence of osteolysis around acetabular component was observed in the ceramic-on-ceramic group (white arrow)

incidence of anatomical restoration was $58.3 \%(7 / 12)$ in the non-ORIF group and $42.9 \%(9 / 21)$ in the ORIF group $(p=0.12)$. It was shown that anatomical restoration was not associated with fracture treatment $(r=0.248$, $p=0.163)$. What is more, there was also no clear evidence that ORIF could improve the long-term outcomes of the subsequent THA. Ranawat et al. [16] also hypothesized that initial ORIF was not an essential procedure before THA and that anatomical restoration was not related to fracture treatment. Moreover, there was an increased risk of infection, peri-articular ossification, and scar tissue, and the presence of retained hardware increased the duration of surgery and blood loss [6, 28].

Ranawat et al. [16] reported that acetabular component survival rate was $97 \%$ with aseptic loosening and $79 \%$ with revision for any reason. Bellabarba et al. [13] also described a 10-year survival rate of $97 \%$ after uncemented acetabular reconstruction. In our study, we demonstrated a cementless acetabular component survival rate of $100 \%$ with loosening and $88.9 \%$ with revision for any reason, because of two "sandwich" ceramic liner fractures due to part design defects [30,31]. After performing revision surgery, those two hips had well-fixed implants with no radiolucencies and had good clinical results in the follow-up study. Furthermore, acetabular component survival in both groups was similar regarding any reason at a mean follow-up of 11.5 years (Fig. 3). In brief, complex reconstruction in the non-ORIF group did not affect component survival and none of the hips were revised because of aseptic loosening.

Wear debris from conventional MOP can cause extensive osteolysis, threatening the long-term survival of cementless cups, especially in young patients [32]. Berry and Halasy [33] reported that $67 \%$ of revisions were associated with polyethylene wear and osteolysis. Roth et al. [26] reported that survivorship of the acetabular component declined from $87 \%$ at 10 years to $57 \%$ at 20 years for polyethylene wear or loosening. Similarly, our results revealed that 8 of 12 patients who underwent THA with conventional MOP had partial radiolucent lines at the bone-implant interface (Fig. 4). The most likely explanation for periprosthetic osteolysis in these patients is low patient age (average 45 years) combined with high activity level. Conversely, we did not observe osteolysis in any patient in the ceramic-on-ceramic group. Our previous study demonstrated that THAs using COC suffer significantly reduced wear and demonstrated improved component longevity [17]. On the basis of the data presented, therefore, one could speculate that optimization of long-term results with COC surfaces has the potential to solve the most common problems that result in revision surgery being required in these patients (aseptic loosening and osteolysis).

Our study may have some limitations. First, this was a retrospective study and not a prospective randomized study, which increased the possibility of selection bias. Secondly, the number of patients in the study was relatively small, and further studies involving more participants are anticipated. Finally, the acetabular components used in this study were not uniform and thus may compromise the robustness of the results.

\section{Conclusion}

In conclusion, Delayed THA with previous acetabular fractures is a challenging procedure. Our study found the initial fracture treatment does not influence the functional results and component survival of subsequent THA at long-term follow-up. Although acetabular osteolysis was observed in our patients, we believe that cementless THA with modern ceramic bearing surfaces will eliminate periprosthetic osteolysis and further improve long-term results.

\section{Abbreviations \\ AAOS: American Academy of Orthopedic Surgeons; COC: Ceramic-on- ceramic; IBG: Impaction bone grafting; MOP: Metal-on-polyethylene; ORIF: Open reduction internal fixation; THA: Total hip arthroplasty}

\section{Funding}

This study was supported by the Fundamental Research Funds for the Central Universities (JUSRP11865).

Availability of data and materials

The datasets used and/or analyzed during the current study are available from the corresponding author on reasonable request. 


\section{Authors' contributions}

TW, XJZ, and JYS contributed to the study conception and design. JJZ and CW contributed to the acquisition of data. TW, JJZ, and CW contributed to the analysis and interpretation of data. TW drafted the manuscript, and XJZ and JYS revised it. All authors read and approved the final manuscript.

\section{Ethics approval and consent to participate}

This study has been approved by the Ethics Committee of the First Affiliated Hospital of Soochow University (NO. 20151009). The written consent was obtained from all participants in the study.

\section{Consent for publication}

Not applicable

\section{Competing interests}

The authors declare that they have no competing interests.

\section{Publisher's Note}

Springer Nature remains neutral with regard to jurisdictional claims in published maps and institutional affiliations.

Received: 11 April 2018 Accepted: 7 August 2018

Published online: 22 August 2018

\section{References}

1. Morison Z, et al. Total hip arthroplasty after acetabular fracture is associated with lower survivorship and more complications. Clin Orthop Relat Res. 2016:474(2):392-8.

2. Giannoudis PV, et al. Operative treatment of displaced fractures of the acetabulum - a meta-analysis. J Bone Joint Surg Br. 2005;87b(1):2-9.

3. Briffa $\mathrm{N}$, et al. Outcomes of acetabular fracture fixation with ten years' follow-up. J Bone Joint Surg Br. 2011;93b(2):229-36.

4. Daurka JS, et al. Acetabular fractures in patients aged $>55$ years a systematic review of the literature. Bone Joint J. 2014;96b(2):157-63.

5. Sierra RJ, et al. Acetabular fractures: the role of total hip replacement. Bone Joint J. 2013;95-B(11 Suppl A):11-6.

6. Makridis KG, et al. Total hip arthroplasty after acetabular fracture: incidence of complications, reoperation rates and functional outcomes: evidence today. J Arthroplast. 2014;29(10):1983-90.

7. Romness DW, Lewallen DG. Total hip arthroplasty after fracture of the acetabulum. Long-term results. J Bone Joint Surg Br. 1990;72(5):761-4.

8. Weber M, Berry DJ, Harmsen WS. Total hip arthroplasty after operative treatment of an acetabular fracture. J Bone Joint Surg Am. 1998; 80a(9):1295-305.

9. Jimenez ML, Tile M, Schenk RS. Total hip replacement after acetabular fracture. Orthop Clin North Am. 1997:28(3):435.

10. Mears DC, Velyvis JH. Primary total hip arthroplasty after acetabular fracture (Reprinted). J Bone Joint Surg Am. 2000;82a(9):1328-53.

11. Berry DJ. Total hip arthroplasty following acetabular fracture. Orthopedics. 1999;22(9):837-9

12. Heeg M, Klasen HJ, Visser JD. Operative treatment for acetabular fractures. J Bone Joint Surg Br. 1990;72(3):383-6.

13. Bellabarba $\mathrm{C}$, et al. Cementless acetabular reconstruction after acetabular fracture. J Bone Joint Surg Am. 2001;83-A(6):868-76.

14. Boraiah $\mathrm{S}$, et al. Open reduction internal fixation and primary total hip arthroplasty of selected acetabular fractures. J Orthop Trauma. 2009:23(4):243-8

15. Lai $\mathrm{O}$, et al. Midterm results of uncemented acetabular reconstruction for posttraumatic arthritis secondary to acetabular fracture. J Arthroplast. 2011; 26(7):1008-13.

16. Ranawat A, et al. Total hip arthroplasty for posttraumatic arthritis after acetabular fracture. J Arthroplasty. 2009;24(5):759-67.

17. Wang $T$, et al. Ceramic-on-ceramic bearings total hip arthroplasty in young patients. Arthroplast Today. 2016;2(4):205-9.

18. Lewis PM, et al. Prospective randomized trial comparing alumina ceramicon-ceramic with ceramic-on-conventional polyethylene bearings in total hip arthroplasty. J Arthroplast. 2010;25(3):392-7.

19. D'Antonio JA, et al. Classification and management of acetabular abnormalities in total hip arthroplasty. Clin Orthop Relat Res. 1989;243:126-37.
20. Harris WH. Traumatic arthritis of the hip after dislocation and acetabular fractures: treatment by mold arthroplasty. An end-result study using a new method of result evaluation. J Bone Joint Surg Am. 1969;51(4):737-55.

21. Pollock D, Sychterz CJ, Engh CA. A clinically practical method of manually assessing polyethylene liner thickness. J Bone Joint Surg Am. 2001;83-A(12):1803-9.

22. DeLee JG, Charnley J. Radiological demarcation of cemented sockets in total hip replacement. Clin Orthop Relat Res. 1976;121:20-32.

23. Gruen TA, McNeice GM, Amstutz HC. "Modes of failure" of cemented stemtype femoral components: a radiographic analysis of loosening. Clin Orthop Relat Res. 1979:141:17-27.

24. Engh CA, Bobyn JD, Glassman AH. Porous-coated hip replacement. The factors governing bone ingrowth, stress shielding, and clinical results. J Bone Joint Surg Br. 1987;69(1):45-55.

25. Brooker AF, et al. Ectopic ossification following total hip replacement. Incidence and a method of classification. J Bone Joint Surg Am. 1973; 55(8):1629-32.

26. von Roth $\mathrm{P}$, et al. Total hip arthroplasty after operatively treated acetabular fracture: a concise follow-up, at a mean of twenty years, of a previous report. J Bone Joint Surg Am. 2015;97(4):288-91.

27. Schreurs BW, et al. Bone impaction grafting and a cemented cup after acetabular fracture at 3-18 years. Clin Orthop Relat Res. 2005:437:145-51.

28. Yuan BJ, Lewallen DG, Hanssen AD. Porous metal acetabular components have a low rate of mechanical failure in THA after operatively treated acetabular fracture. Clin Orthop Relat Res. 2015;473(2):536-42.

29. Imase T, Ito T, Morita D. Massive bone defect compromises postoperative cup survivorship of acetabular revision hip arthroplasty with impaction bone grafting. J Arthroplasty. 2014;29(12):2424-9.

30. Kawano $\mathrm{S}$, et al. Failure analysis of alumina on alumina total hip arthroplasty with a layered acetabular component: minimum ten-year follow-up study. J Arthroplast. 2013;28(10):1822-7.

31. Wang T, et al. Mid term results of total hip arthroplasty using polyethyleneceramic composite (Sandwich) liner. Indian J Orthop. 2016:50(1):10-5.

32. Dumbleton JH, Manley MT, Edidin AA. A literature review of the association between wear rate and osteolysis in total hip arthroplasty. J Arthroplasty. 2002;17(5):649-61.

33. Berry DJ, Halasy M. Uncemented acetabular components for arthritis after acetabular fracture. Clin Orthop Relat Res. 2002;405:164-7.

\section{Ready to submit your research? Choose BMC and benefit from:}

- fast, convenient online submission

- thorough peer review by experienced researchers in your field

- rapid publication on acceptance

- support for research data, including large and complex data types

- gold Open Access which fosters wider collaboration and increased citations

- maximum visibility for your research: over $100 \mathrm{M}$ website views per year

At $\mathrm{BMC}$, research is always in progress.

Learn more biomedcentral.com/submissions 